II Simpósio de Comunicação Científica

\author{
UFSC \\ (5 e 6 de maio de 2008)
}

\title{
A Comunicação Científica no Brasil: estratégias de diálogo científico em âmbito internacional
}

Fomento e financiamento às editoras cientificas (universidades...) pelo CNPq e FAPS 


\section{Sociedade Brasileira de Química - SBQ}

- julho de 1977 -

(desenvolvimento e consolidação da sociedade, divulgação da Química e de suas relações, aplicações e conseqüências para o desenvolvimento do país e melhoria da qualidade de vida dos cidadãos)

No. de sócios: 3.600 ( 3.175 efetivos)

Revistas (periódicos):

- Química Nova (QN) - Quim. Nova

- Química Nova na Escola (QNEsc)

- J ournal of the Brazilian Chemical Society (.Braz.Chem.Soc.) 


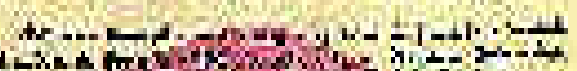

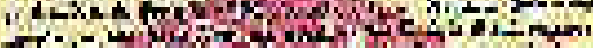

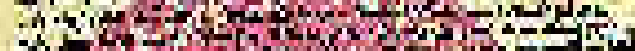

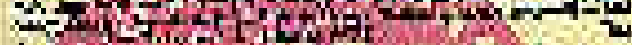

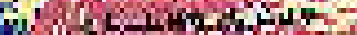

ist...M.MW

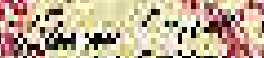

Pring

PISH

trithin.

Antipl

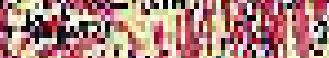

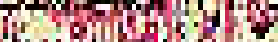

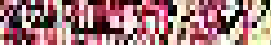

- Hitit.

$7+1+$

i)

3

$x^{2}+7-4+43$

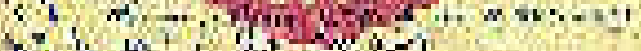

, $1,1, \infty$.

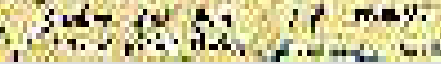

Quim. Nova 1978,

vol.1, no.1
- Artigos originais, revisões, trabalho/artigo sobre educação superior e história da Química

- Português, Inglês e Espanhol

- Referees nacionais e estrangeiros

- 8 edições/ano (tiragem 4.200/edição; gratuita para sócios)

- Editores (3), Cons. Editorial (16) 


\section{química nova in}

Ensino das cienciasy perspectivas

ibero-americanas

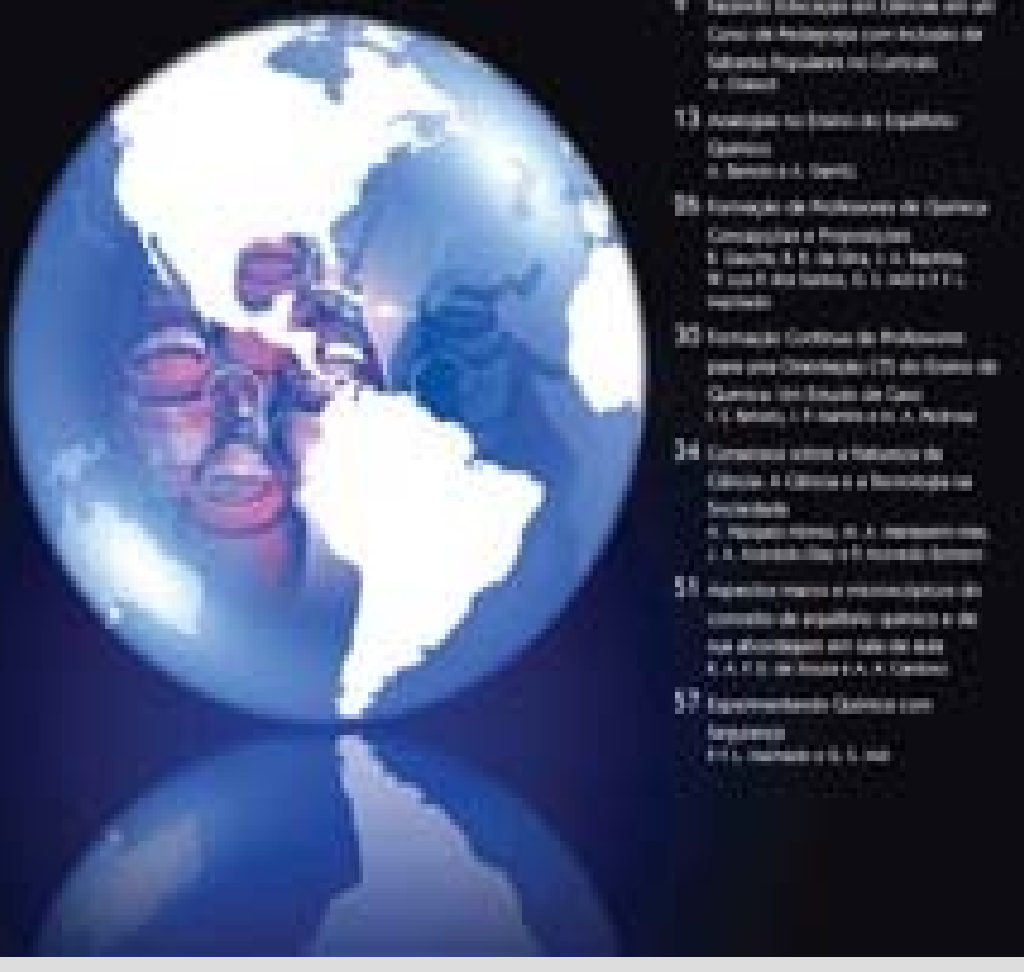

I nício 1995
- Subsidiar o trabalho, a formação e a atualização da comunidade do Ensino de Química (estimular debate e reflexões sobre o ensino e a aprendizagem)

- Artigos originais

- Trimestral (em 2008) - (assinaturas)

- Editores (3); Conselho Editorial (14)

- Apoio (a projetos): CNPq

- Professores do ensino médio/fund. (cócin) recobom aratuitamonto

- Custo atual (anual):

100 mil (impressão + composição + diagramação) 


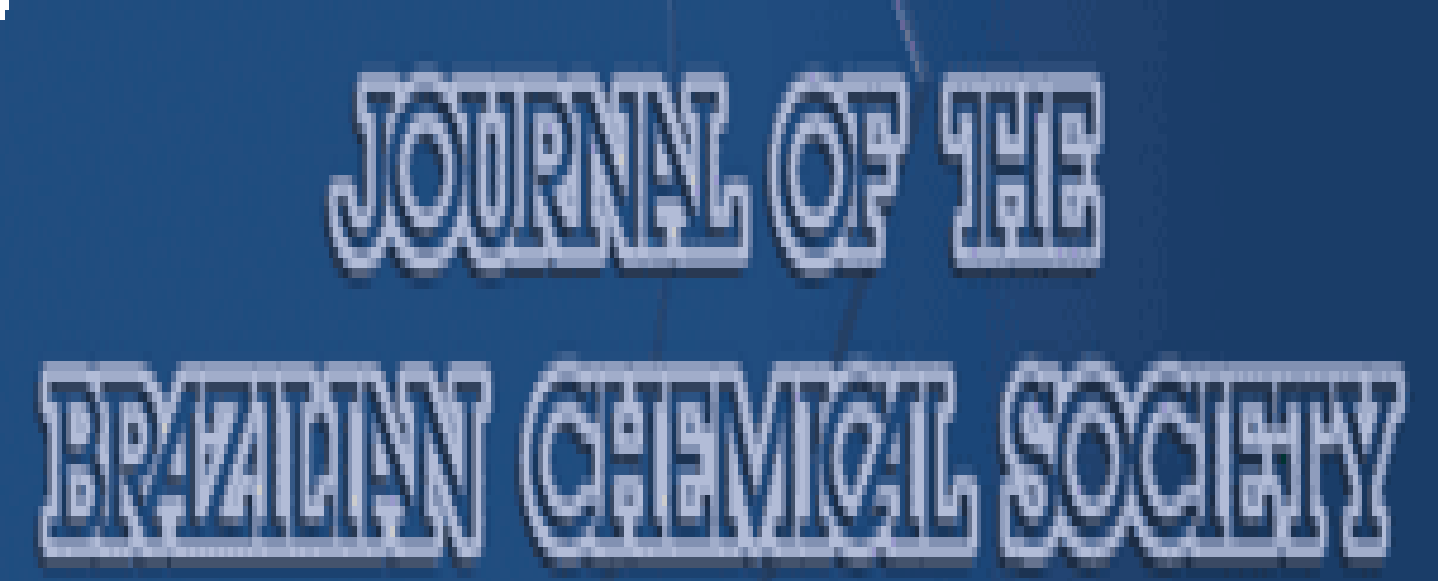

- 8 edições/ano - Inglês Apoio: CNPq, FAPESP, MCT

- Versões: online e impressa (1990)

- Todos os aspectos da Ouímica exceto educacão filosofia_e história da Química • Custo anual (atual):

- Indexação: Science 160 mil (impressão + composição Chemistry Citation I Earth Sciences); CA + diagramação); (270 mil)

- Editores (6); Editore

- Tiragem/edição: 600 (assinaturas) - Edições extras custeadas pelos

- Conselho Editorial (1 interessados 
Produção de periódicos científicos eletrônicos

"Sistema Eletrônico de Editoração de Revistas" (SEER)

Customizado pelo ibict

Software livre - desenvolvido pelo "Public Knowledge Projetc" (Open J ournal Systems),

Universidade de Bristish Colúmbia

Desde 2004:

- mais de 800 pessoas treinadas

- surgimento de 370 revistas eletrônicas 


\section{PL 1120/2007 (Dep.Rodrigo Rollemberg)}

“... ampliar a disseminação da produção técnicocientífica pelas IES e unidades públicas de pesquisa, obrigando-as a construírem repositórios institucionais para depósito da produção técnicocientífica de seus discentes e docentes, da graduação à pós-graduação".

O acesso aos conteúdos a serem disponibilizados será totalmente livre e gratuito. O I bict será responsável pelo armazenamento e oferta, na web, desses conteúdos/conhecimentos. 
I ncubadora de Revistas Científicas

\section{Digitais - INSEER}

"Apoiar e estimular a construção e a manutenção de revistas científicas de acesso livre na internet".

A comunidade editorial científica terá um ambiente de alta visibilidade, com as facilidades de gestão e manutenção de uma revista científica... 


\section{FAPEMIG}

Programa: Apoio à publicação de artigos que divulguem resultados de pesquisas (financiadas ou não pela FAPEMIG) desenvolvidas em instituições sediadas no estado de Minas Gerais em revistas indexadas no ISI ou no SCIELO.

Requisito do Solicitante: ter o trabalho aceito para publicação em revista indexada.

Limitante: US\$ 1.000,00 por pesquisador/ano. 
- O apoio à publicação de periódicos é de caráter excepcional e proporcional à contribuição dos pesquisadores do Estado de São Paulo (periódicos veiculando trabalhos de pesquisa, inéditos e avaliados por pares, indexados, com padrão editorial definido).

Serão priorizados os periódicos de veiculação eletrônica no Scielo, financiado pela FAPESP. 
- O artigo tem de ser resultado de pesquisa apoiada pela FAPESP a ser divulgado em periódico internacional especializado com rigorosa política editorial (separatas, não).

- O livro deve expor resultados originais e inéditos de pesquisa realizada pelo pesquisador 


\section{Produção e divulgação Científica e Tecnológica:}

Apoiar a produção e a divulgação científica e tecnológica no Estado do Rio de J aneiro, por meio de livros, manuais, números especiais de revistas (publicações temáticas), coletâneas científicas, vídeos, CDs e DVDs.

\section{Auxílio à Editoração:}

Apoiar a edição de livros, manuais, números especiais (temáticos) de revistas, coletâneas científicas em qualquer tipo de suporte, vídeos, CDs e DVDs. 


\section{Apoio a Publicações Científicas \\ (Programa Editorial)}

C A P E S

Termos de referência:

- Indexação pelo I SI (fator de impacto)

- Conceito QUALI S (internacional A...)

- Revista de Sociedade (abrangência)

- Conceitos dos Programas de PG (CAPES) afins 


\section{(Programa Editorial - 2007 -)}

C A P E S

Grande Área

Projetos

59

36

61

23

No. Projetos: 390
C.Sociais Aplicadas

Engenharias

Lingüística, Letras $€$

Não informado
(280 pesquisadores)

Total R\$: 7.026.439,00 


\section{O MCT e a difusão da ciência no Brasil}

\section{Departamento de Popularização e Difusão de Ciência e Tecnologia/ SECIS/MCT}

(Ildeu de Castro Moreira) 


\section{Quadro atual - Divulgação da C\&T}

- Crescimento expressivo nas últimas décadas: maior presença na mídia, centros e museus de ciência, eventos de divulgação etc. Mas ainda frágil e limitado.

-Atuação restrita (embora crescente) de universidades, institutos de pesquisa e de organismos públicos. Pequena valorização acadêmica da atividade.

- Ensino de ciências e matemática muito deficiente na educação básica.

- Cobertura deficiente e freqüentemente de qualidade inferior nos meios de comunicação. Interfaces entre a ciência e a cultura freqüentemente ignoradas.

- Raras atividades de popularização da C\&T junto às camadas mais pobres.

- Necessidade de políticas públicas bem definidas. 


\section{Diretrizes para uma política de popularização da C\&T}

- Contribuir para:

-aumento da apreciação coletiva da importância da C\&T no mundo moderno;

•estímulo à curiosidade, criatividade e inovação;

• diminuição da "exclusão do conhecimento";

•estabelecimento de uma cultura científica na sociedade.

- Promover a melhoria e uma maior atualização/modernização do ensino das ciências em todos os níveis de ensino. Ênfase nas ações e atividades que valorizem a criatividade, a experimentação e a interdisciplinaridade.

- Buscar maior presença da C\&T brasileira nos meios de comunicação.

- Estimular o uso e a difusão da C\&T em ações de inclusão social e redução das desigualdades. Levar em conta a diversidade ambiental, cultural, étnica, etc. 


\section{Diretrizes para uma política de popularização da}

\section{C\&T}

- Promover o aumento da participação na C\&T de jovens de todos os segmentos.

- Estimular que as atividades de PC\&T não se restrinjam às áreas de ciências exatas e naturais, mas que incorporem também as ciências sociais e humanas.

- Respeitar e reconhecer os conhecimentos populares e tradicionais. Proteger o meio ambiente e o desenvolvimento sustentável.

- Estabelecer parceria em atividades de popularização da C\&T com governos estaduais e municipais, outras áreas do governo federal, entidades de C\&T, empresas estatais e privadas, universidades e instituições de pesquisa...

- Estimular e promover maior participação popular nas questões gerais de C\&T. 


\section{Linhas prioritárias para a PC\&T - 2004/ 07 - MCT}

1. Apoio a centros e museus de ciência. Programa Ciência Móvel.

2. Presença maior e mais qualificada da C\&T na mídia. Parceria com TVs, rádios e jornais.

3. Colaboração na melhoria do ensino de ciências nas escolas: olimpíadas, feiras de ciências, concursos, material escolar...

4. Criação e consolidação da Semana Nacional de C\&T.

5. Apoio a eventos nacionais de/sobre divulgação científica.

6. Apoio à formação de comunicadores em ciência.

7. Valorização acadêmica das atividades de divulgação científica.

8. Cooperação com governos e organismos internacionais (MercoSul, UNESCO, OEA, Ciência Viva, Cyted, ...) 


\section{Editais para divulgação científica - 2004/ 07}

...12) Chamada Pública para Conteúdos Digitais Educacionais na Internet [MEC e MCT, colaboração DEPDI-SECIS] - R\$75.000.000,00 - 19 grandes projetos - 2007/2008.

13) Edital para Divulgação Científica - [CNPq/DEPDI SECIS] - R\$ 7.000.000,00 - 2007 - 1.200 projetos 


\section{PACTI - 2007-2010 - Prioridades Estratégicas}

I - Expansão e Consolidação do Sistema Nacional de C,T\&l

II - Promoção da Inovação Tecnológica nas Empresas

III - Pesquisa, Desenvolvimento e Inovação em áreas estratégicas

IV - C\&T para o Desenvolvimento Social:

1. Popularização da C\&T e melhoria do Ensino de Ciências

2. Tecnologias para o desenvolvimento social 


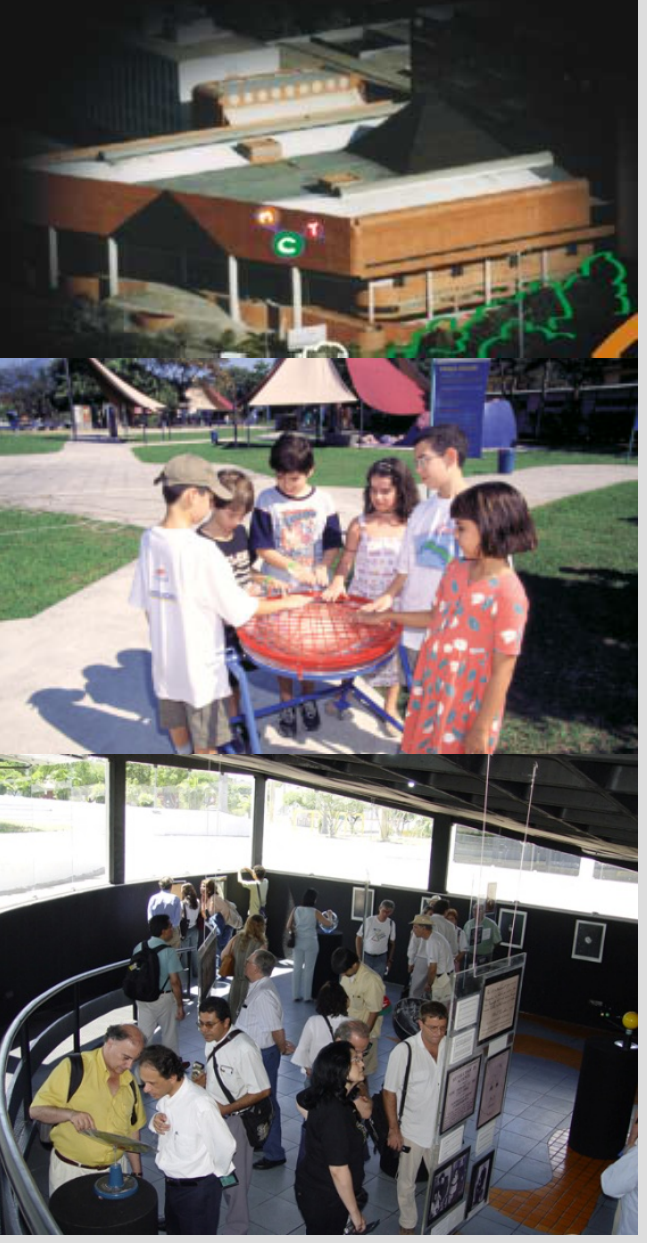

Apoio a centros e museus de ciência

- Incubação e manutenção de centros e museus de ciência (Brasília, Teresina, São Luís, Aracaju, Maceió, Ilhéus, Fortaleza, Florianópolis, etc.).

- Organização de encontros e oficinas sobre museus de ciência.

- Catálogo Nacional de Centros e Museus de Ciência.

- Participação no Sistema Gestor de Museus.

$4^{\circ}$ Congresso Mundial de Centros de Ciência 2005 - Rio de Janeiro

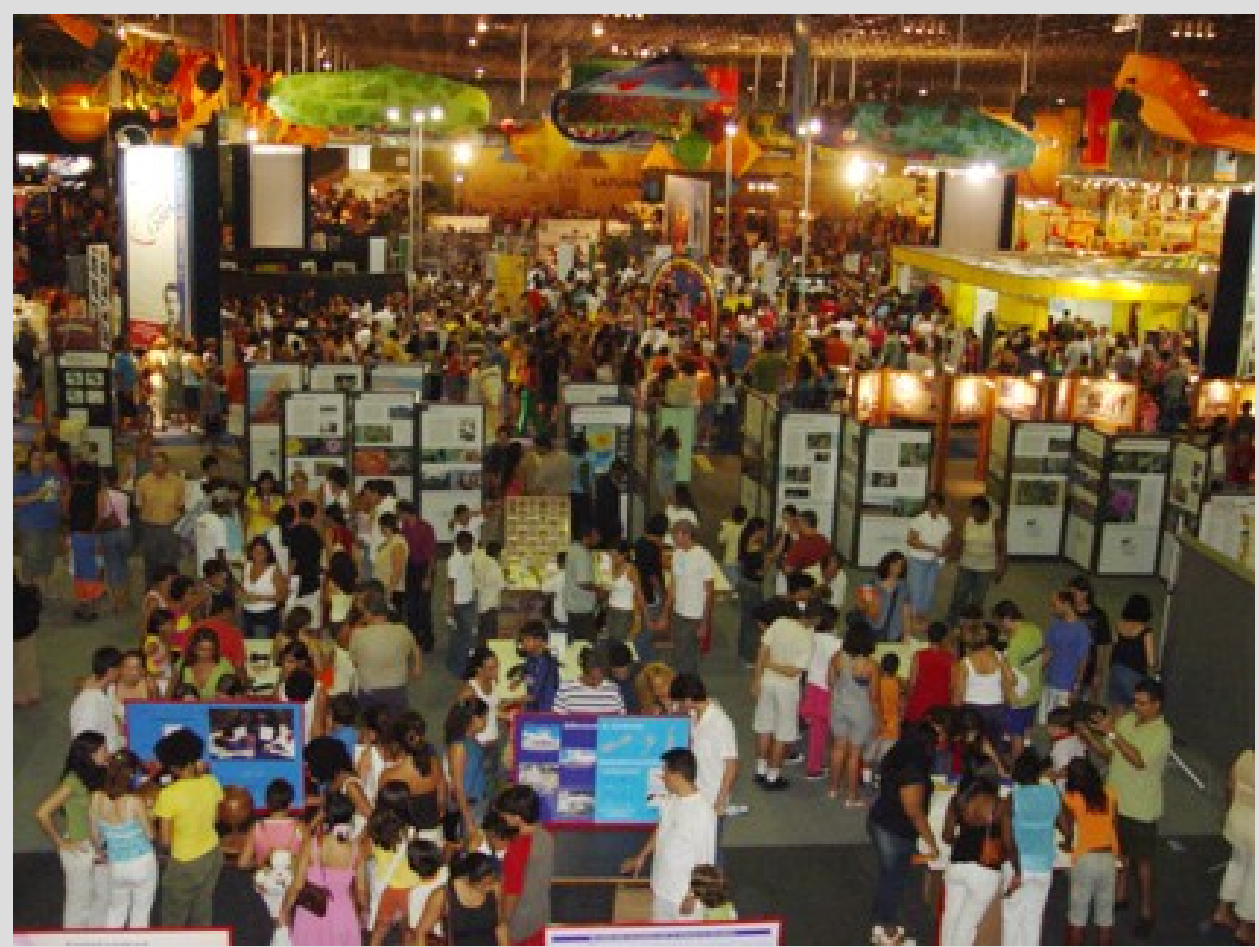




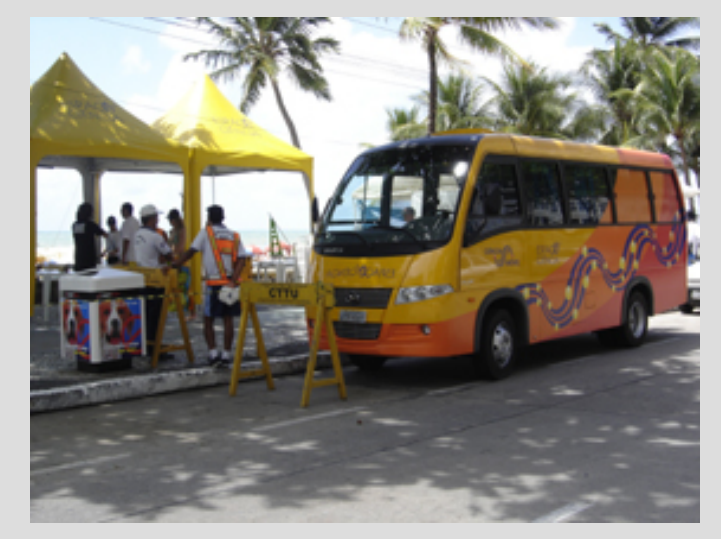

\section{Pernambuco}

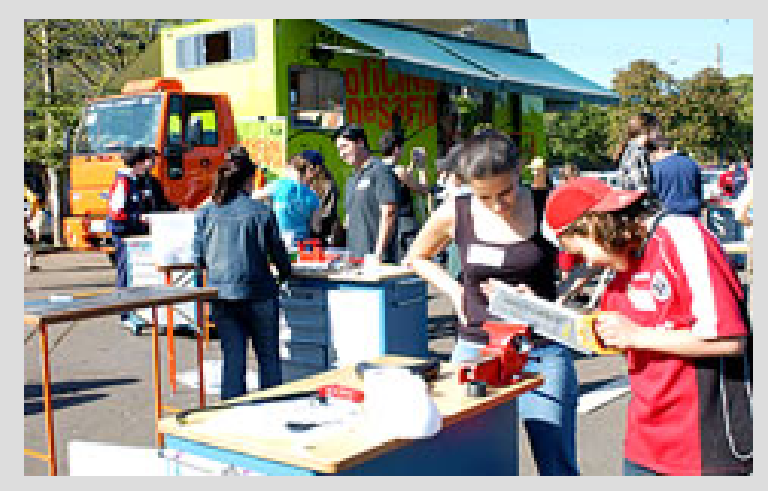

São Paulo

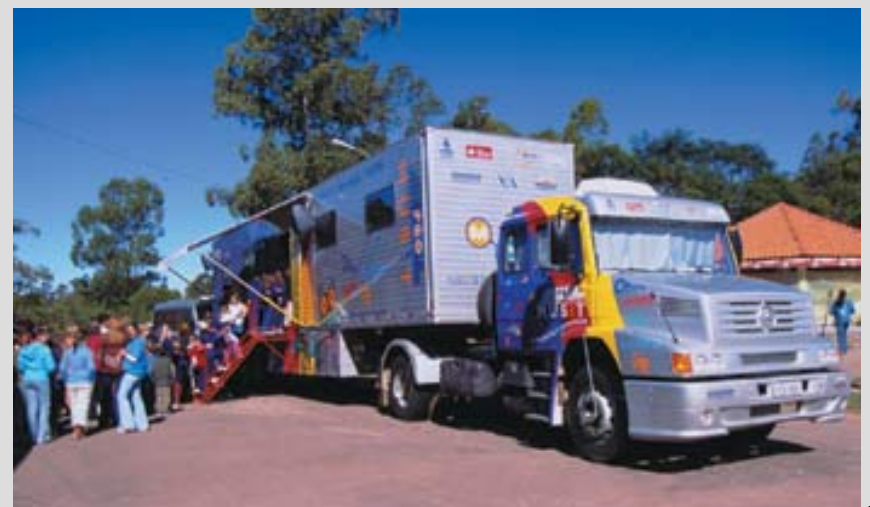

Ciência Móvel Vida e Saúde para Todos A Fundaçăo Oswaldo Cruz/Museu da Vida e a Fundaçắo Centro de Ciências e Educaçăo Superior a Distância do Estado do Rio de Janeiro

têm o prazer de convidar para a cerimóna de inauguraçáo do projeto Ciência Móvel: Vida e Saúde Para Todos, a ser realizada no dia 06 de outubro, às $12 \mathrm{~h} 30$, no auditório

06 de outubro de 2006

$12 \mathrm{~h} 30$

Fiocruz

Av. Brasil, 4365 | Manguinhos

Auditório Museu da Vida

Mais informaçôes: (21) 2568.1226

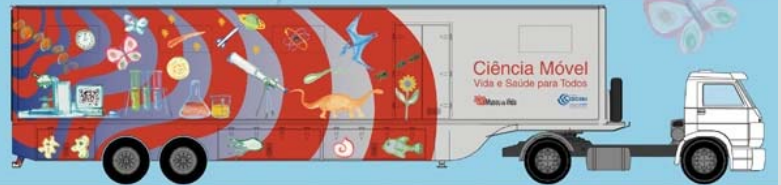

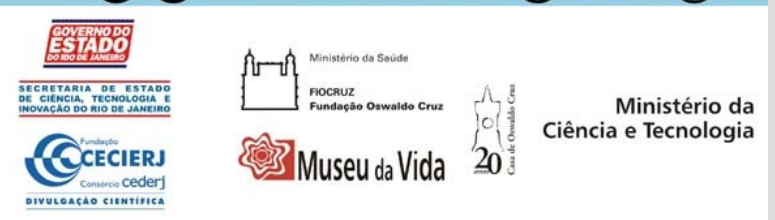

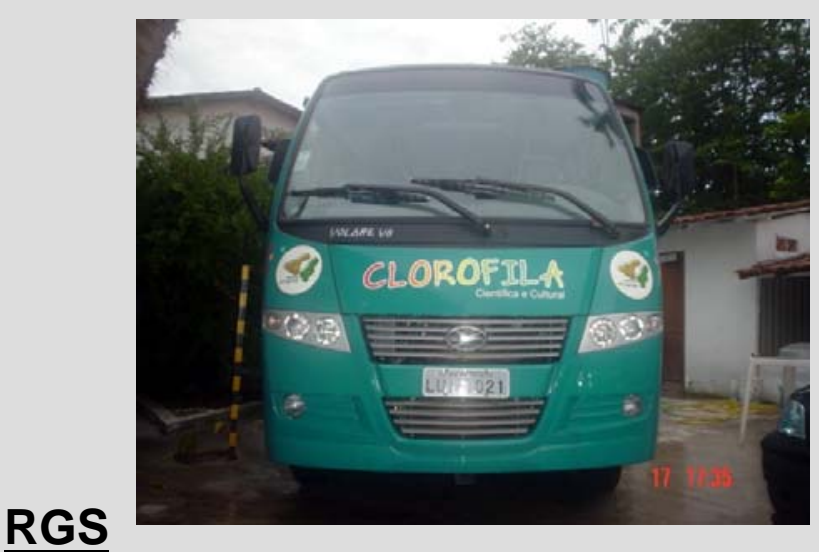

Pará

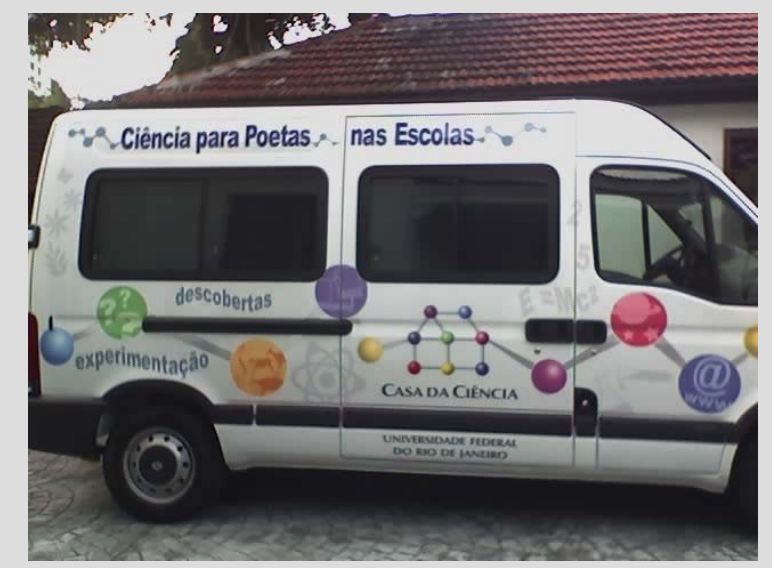

Rio de Janeiro

Programa Ciência Móvel: Veículos com ciência itinerante 
Olimpíadas e feiras de ciência

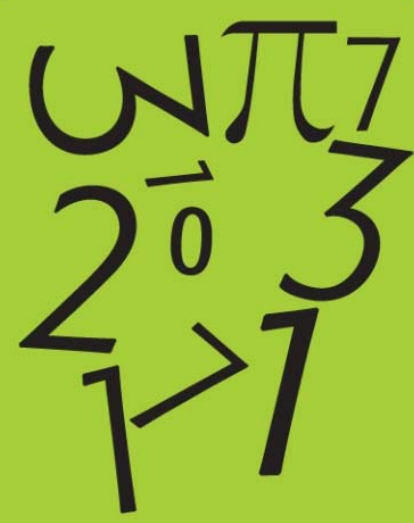

1a OLIMPÍADA BRASILEIRA DE MATEMÁTICA DAS ESCOLAS PÚBLICAS

O B M EP 2005

Somando novos talentos para o Brasil
2005: 10,5 milhões de estudantes 2006: 14 milhões de estudantes 2007: 17,3 milhões (82\%) $65 \%$ : escolas 96\%: municípios

Parceria com MEC, IMPA e SBM

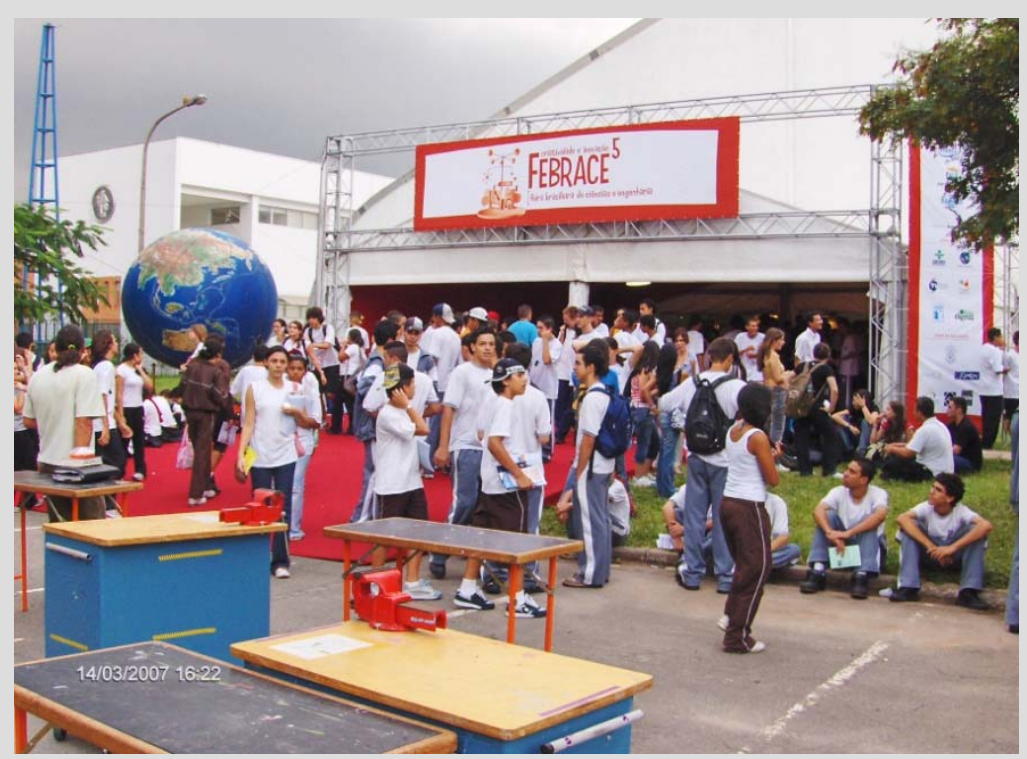

Feiras de Ciência: Febrace 


\section{Programa VerCiência}

Cerca de 20 DVDs com vídeos de divulgação científica distribuídos gratuitamente para todos os estados do país (Semana Nac de C\&T - 2005/2007) e (alguns) no site da RNP/MCT

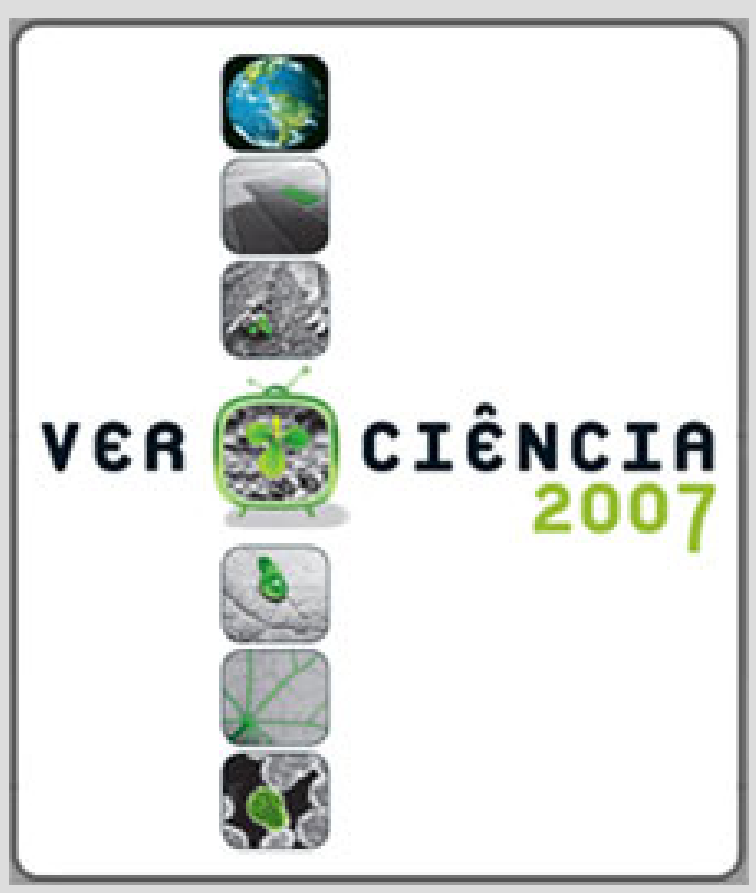

\section{Programa OuvirCiência}

160 programas de rádio de divulgação de C\&T distribuídos gratuitamente para todos os estados do país (Semana Nacional de C\&T - 2006/2007) e no site do MCT

\section{Rádio \& Ciência o!pey ou e! Juว̆!J}

Dias 20 e 21 de junho de 2006

- Apresentação de experiências de ciência

no rádio (Brasil e Europa)

Discussão sobre uma política para divulgação ientífica no rádio
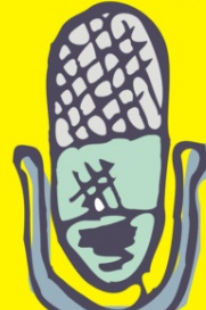

Local:

Auditório do Ministério da Ciência e Tecnologia Esplanada dos Ministérios Bloco E - Brasília · DF mex

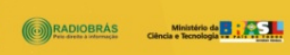




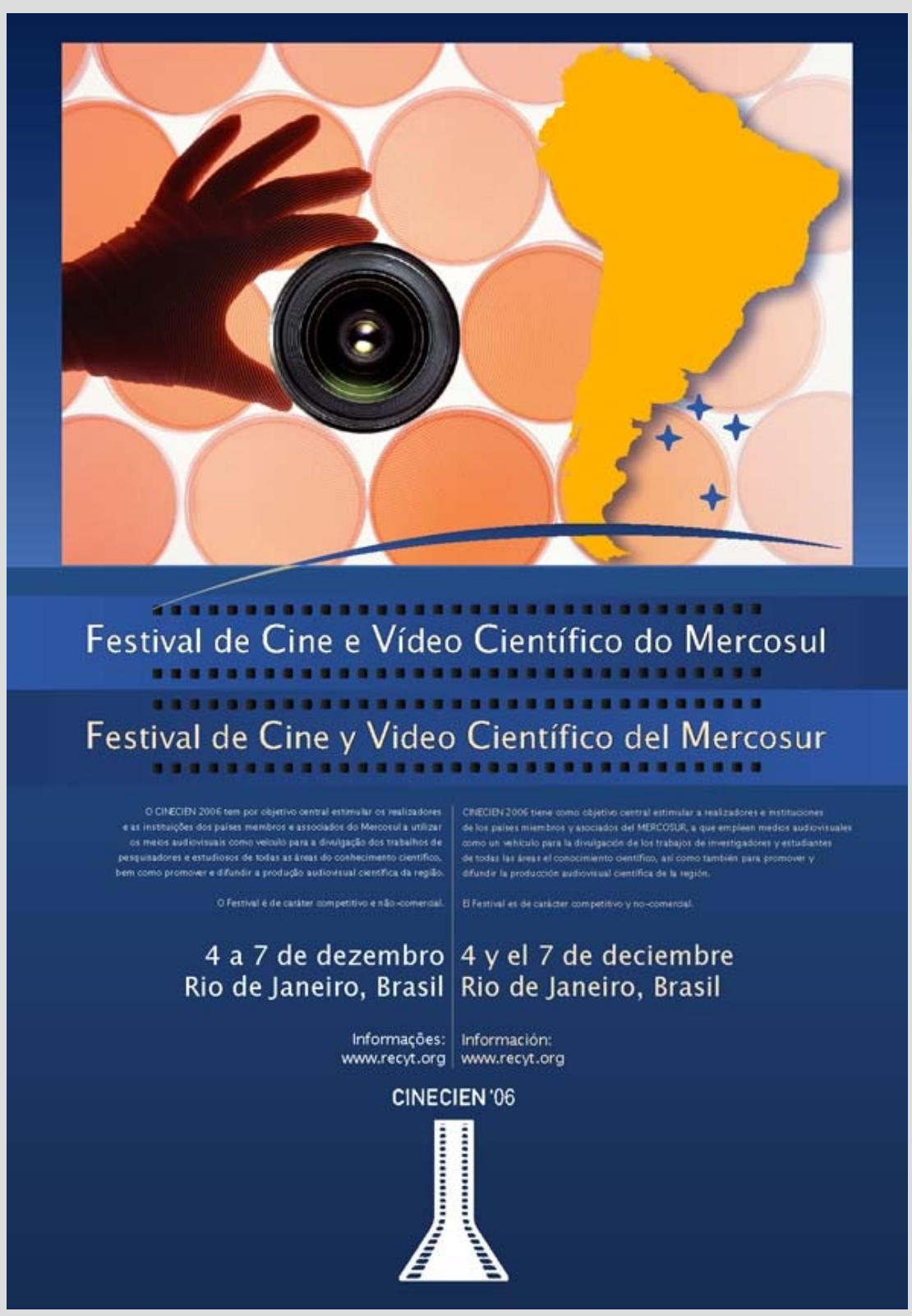

\section{Ciência Vale a Pena}

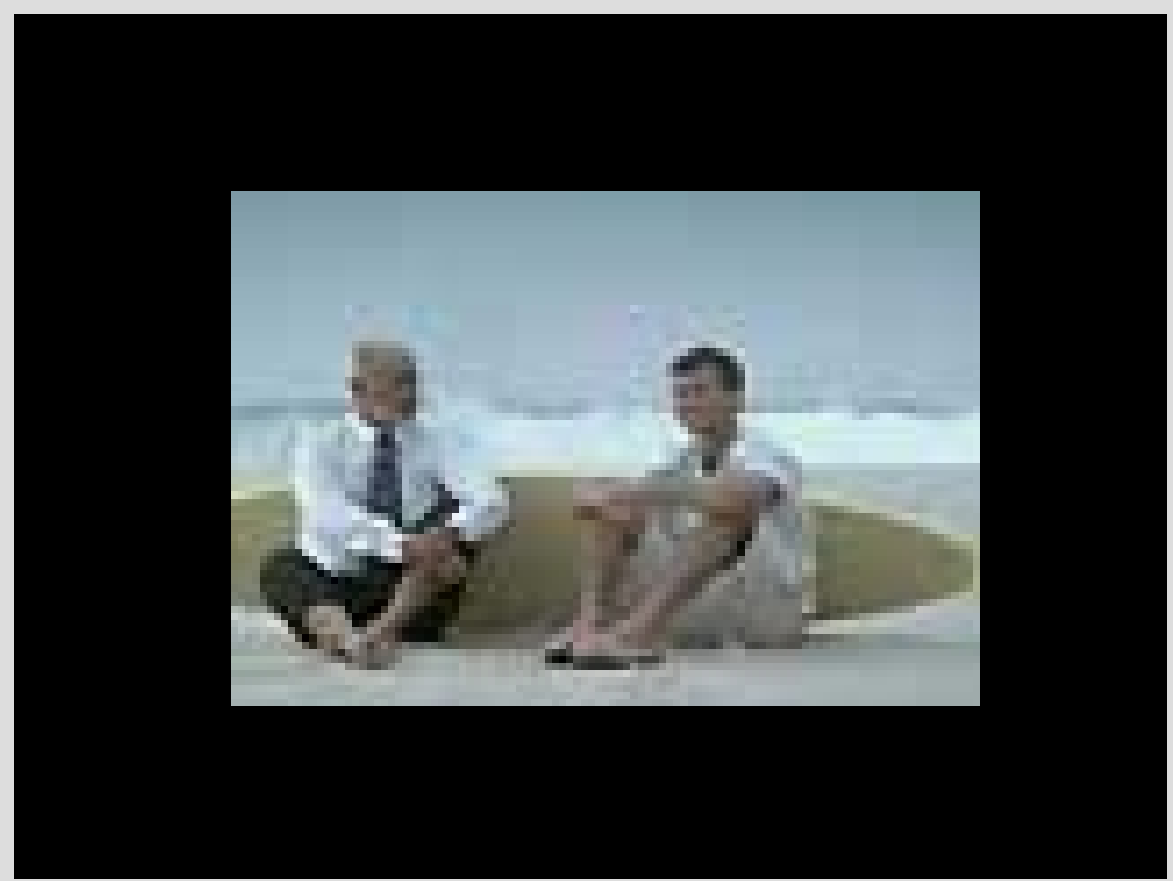

\section{TV e Cinema.}


Q1a. Vou ler a seguir uma lista de assuntos. Por favor, diga-me se você tem muito interesse, pouco interesse interesse ou nenhum interesse em cada um deles.

Política

Medicina e saúde

Arte e cultura

Meio Ambiente Ciência e Tecnologia|

Esportes

Moda

Economia

Religião

$$
20
$$

60

38

58

41

47

28

40

51

57

$20 \%$

44

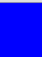

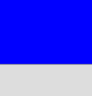
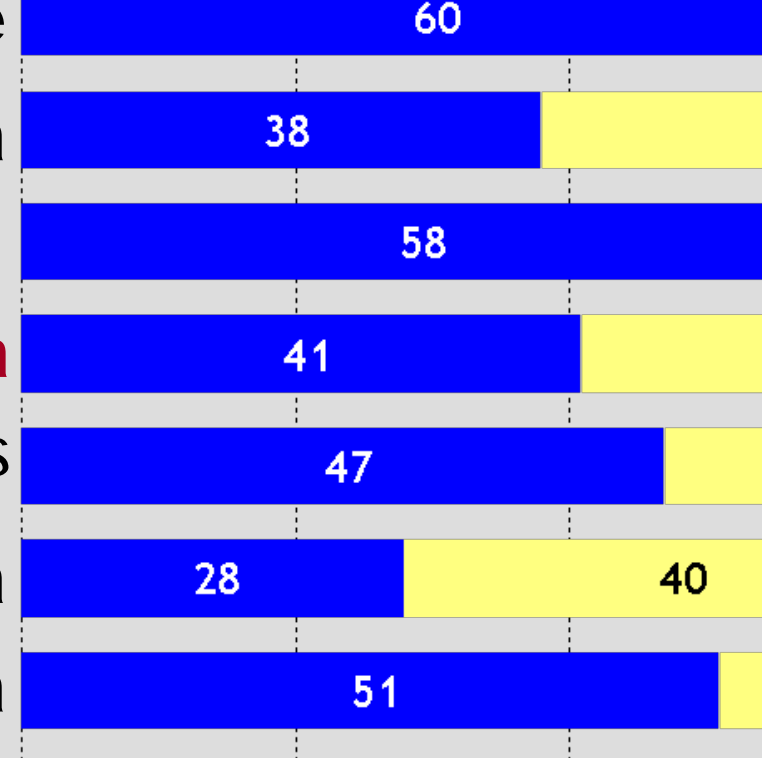

$0 \%$

$40 \%$

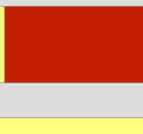

31

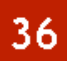

1,84

$9 \quad 2,52$

40

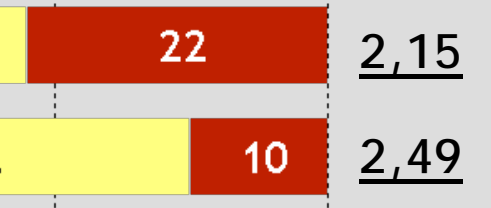

35

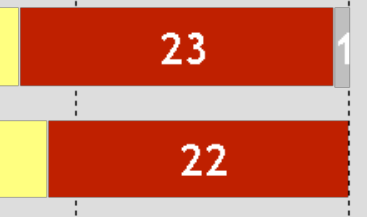

32

2,18

$\underline{2,25}$

1,96

36

$13 \quad 2,38$

33

10

$\underline{2,47}$

$60 \%$

$80 \%$

100 ;

D - Muito interesse $\quad 2$ - Pouco interesse $\quad 1$ - Nenhum interesse $\quad$ Não Sabe/ Não respondeu

Base: total da amostra 2004 entrevistas 


\section{Meios de informação \\ sobre C\&T} Q5. Vou ler algumas frases para você. Para cada uma delas responda, por favor, com as seguintes opções:

Vê programas na TV

Ouve no rádio

Lê emjornais

Lê em revistas

Lê na internet
15

21

5

12

12

29

47

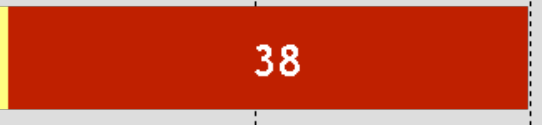

74

32

56

59

77

29 $\underline{1,77}$

$\underline{1,31}$

$\underline{1,57}$

$\underline{1,54}$

$\underline{1,32}$

$\underline{1,50}$

$\underline{1,10}$

Assina manifestos, participa de manifestações 27 ou protestos em questôes de c\&t

$$
\begin{array}{llllll}
0 \% & 20 \% & 40 \% & 60 \% & 80 \% & 100
\end{array}
$$

- 3 - Sim com frequiência 2 - Sim, de vez em quando 1 - Não, nunca Não respondeu 
Q3. Vou ler uma lista de locais ou acontecimentos públicos de C\&T. Por favor, diga-me se você visitou algum deles ou participou de algum destes eventos ao longo últimos 12 meses.

Espontânea, Resposta múltipla

$52 \%$

$3 \%$

Museu ou

Atividade Biblioteca centro De C\&T da Semana Nacional de Ciência e Tecnologia pública

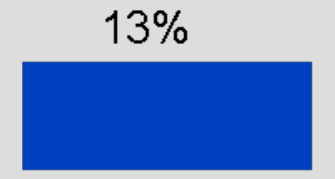

Feira de ciências ou olimpíada de ciências ou de matemática
$12 \%$

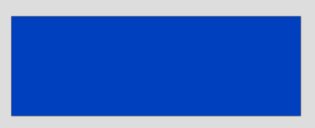

Museu de arte a

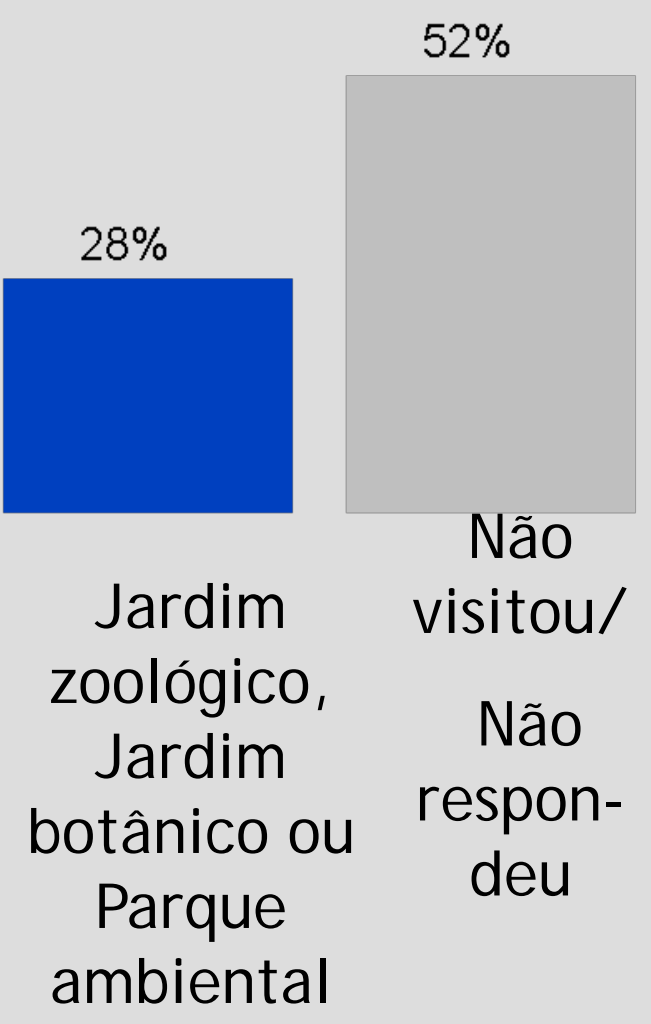

Base: total da amostra 2004 entrevistas 


\section{Não-visitação de museu/centro de C\&T - Razões}

Q4a. [PARA AQUELES QUE NÃO VISITARAM UM MUSEU OU CENTRO DE CIÊNCIA E TECNOLOGIA]: Há alguma razão pela qual você não tenha visitado (últimos 12 meses)

Eles não existem na minha região $35 \%$

Não tem tempo para ir $31 \%$

Não está interessado $22 \%$

Não sabe onde existem museus $19 \%$

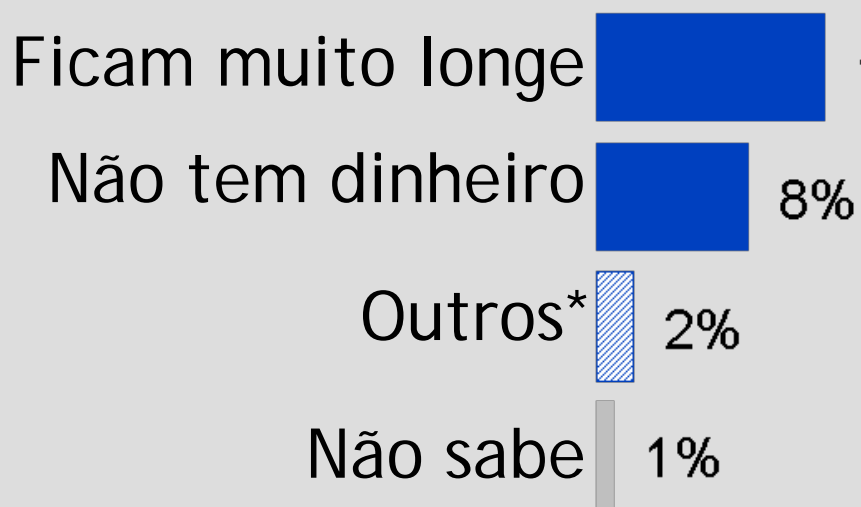

\section{$\%$}




\section{C\&T: percepção de benefícios}

Q9. A ciência e a tecnol ogia trazem mais benefícios ou mais mal efícios para a humani dade?

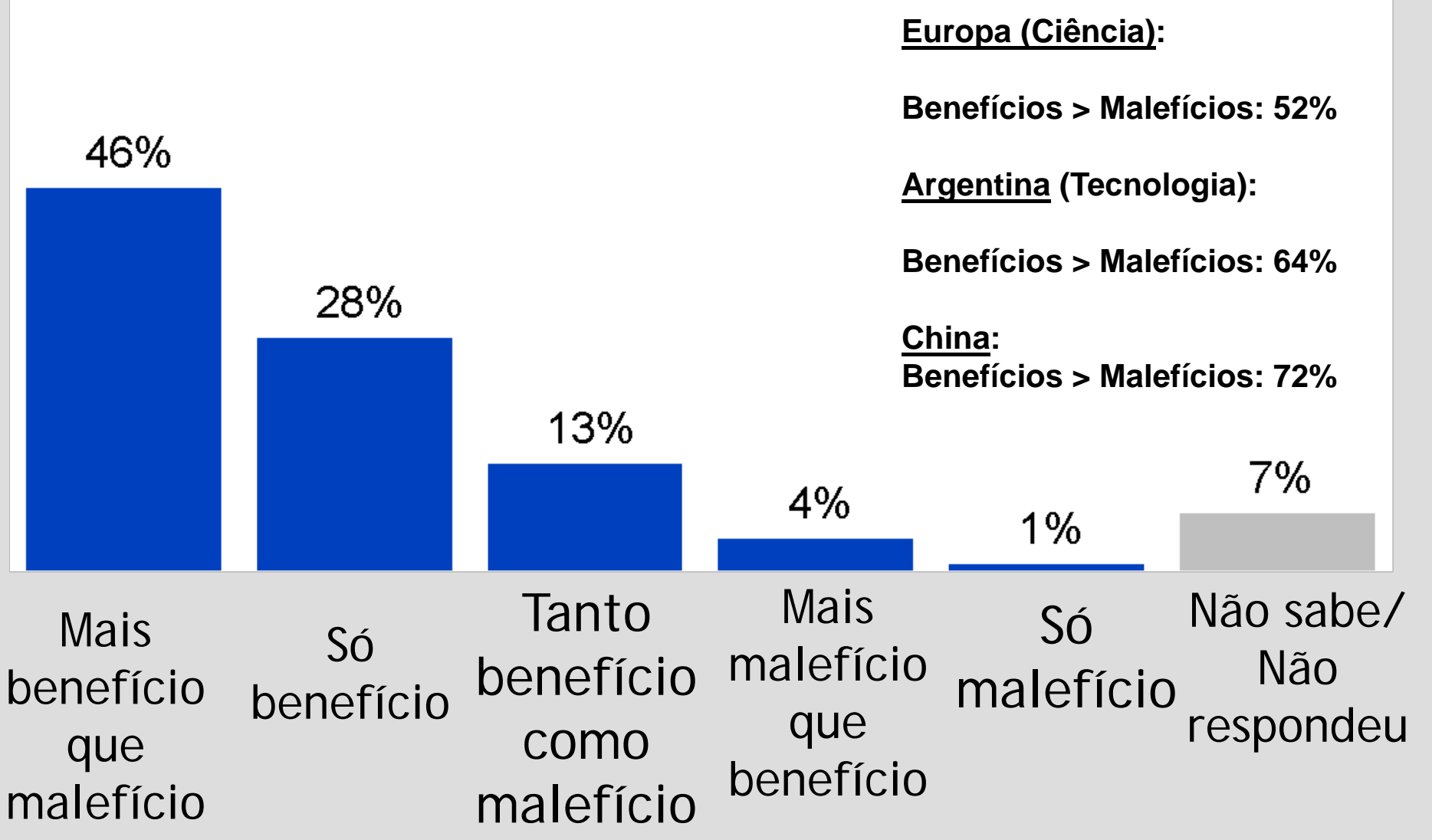




\section{C\&T - Malefícios}

Q10b. Quais malefícios?

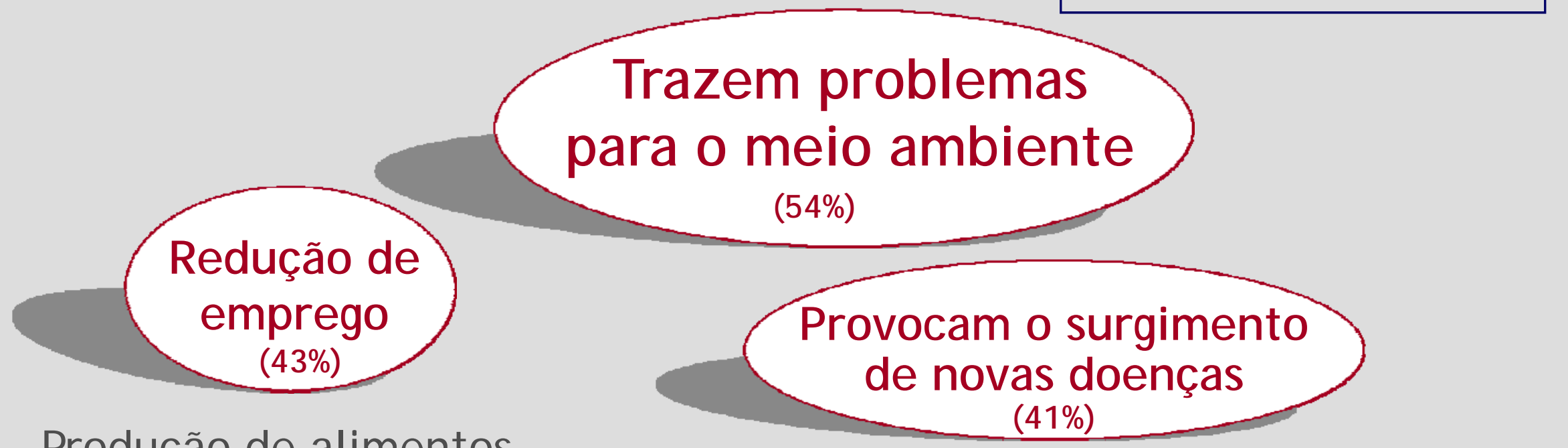

Produção de alimentos menos saudáveis

(32\%)

Mau uso da internet/ tráfico de drogas pela internet

$(3 \%)$

Desenvolvimento de bombas nucleares/ atômica

$(5 \%)$

$(2 \%)$

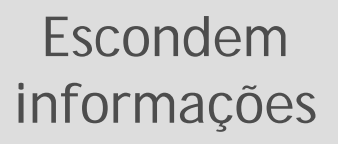

Escondem informações
Prej uízos para saúde $(2 \%$

Aumento das desigualdades $(21 \%)$
Prej udica o desenvolvimento/ crescimento das crianças $(4 \%$ 


\section{Conhecimento de Instituições}

Q22. Conhece alguma instituição que se dedique a fazer pesquisa científica em nosso país?
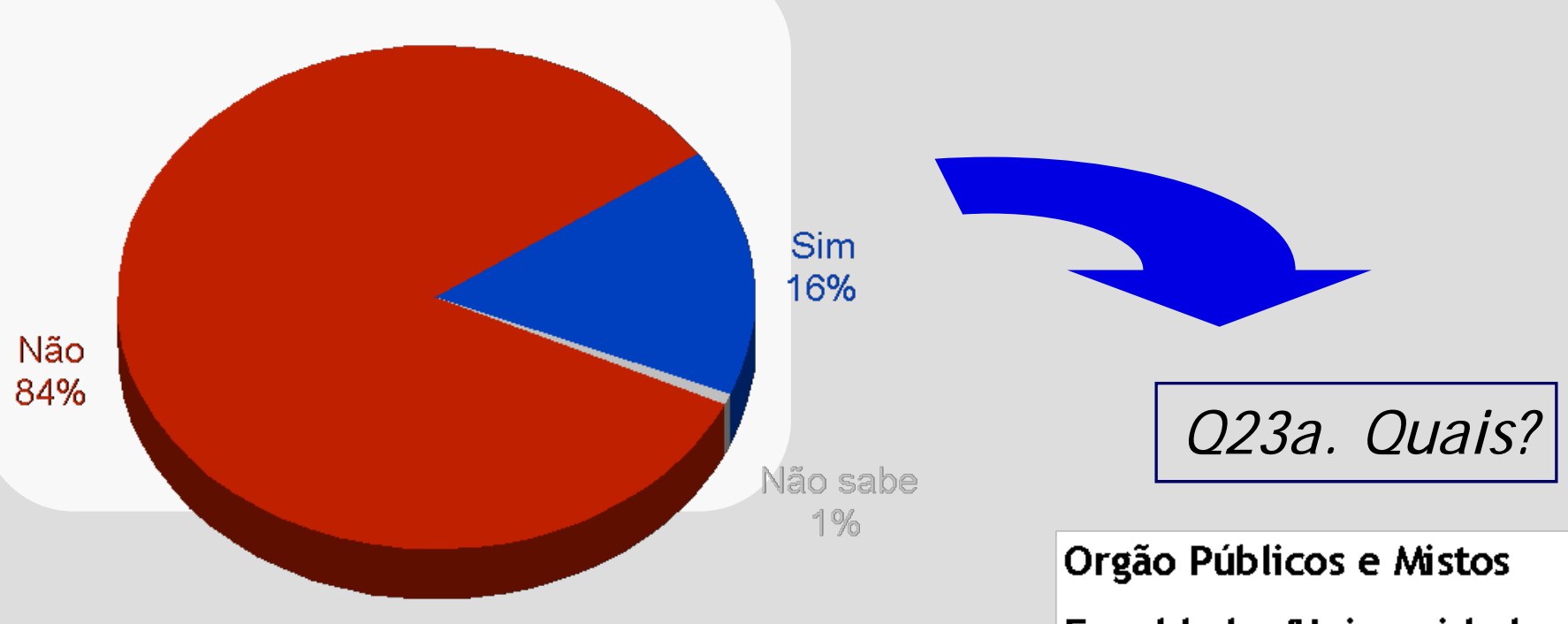

Orgão Públicos e Mistos

$47 \%$

Faculdades/Universidades/Escolas

$46 \%$

Empresas

$23 \%$

Hospitais

$5 \%$

Fundações e Entidades Privadas

$3 \%$

Outras menções

$11 \%$

Base: total da amostra 2004 entrevistas 


\section{CIÊNCIA E ARTE}

Cartola/Carlos Cachaça (1948)

\section{Cartola70anos}

Tu és meu Brasil em toda parte

Quer na Ciência ou na Arte

Portentoso e altaneiro

Os homens que escreveram tua história

Conquistaram tuas glórias

Epopéias triunfais

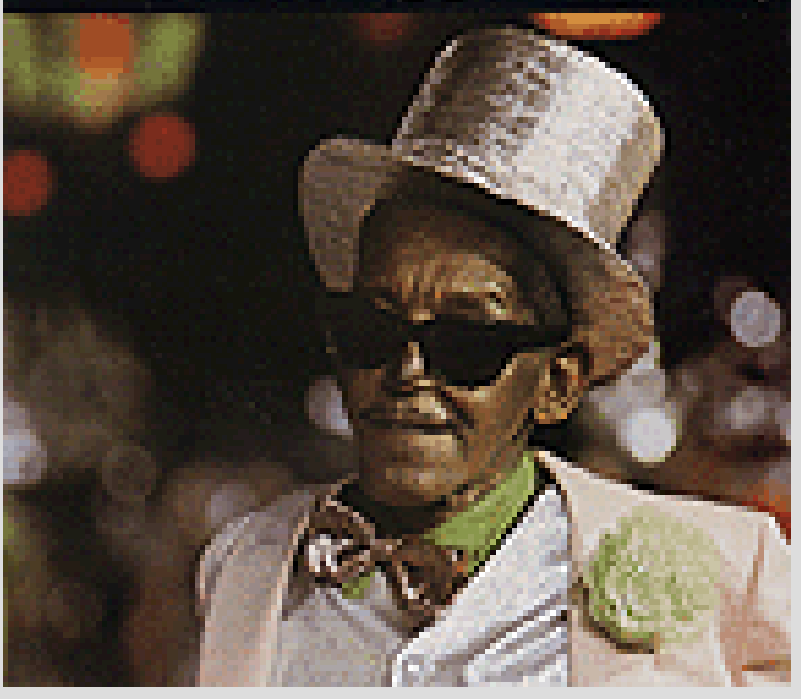

Quero neste polbre enredo

Reviver glorificando os nomes teus

Levá-los ao Panteão dos grandes imortais

Pois merecem muito mais

Vou querendo levá-los ao cume da altura

Cientistas tu tens e tens cultura

E nos rudes poemas destes pobres vates

Há sábios como Pedro Américo e Cesar Lattes. 
XOTE ECOLÓGICO

Aguinaldo Batista e Luiz Gonzaga (1989)

Não posso respirar, não posso mais nadar

A terra tá morrendo, não dá mais pra plantar

Se a planta não nasce se nasce não dá

Até pinga da boa é difícil de encontrar

Cadê a flor que estava ali?

Poluição comeu.

E o peixe que é do mar?

Poluição comeu

E o verde onde que está ?

Poluição comeu

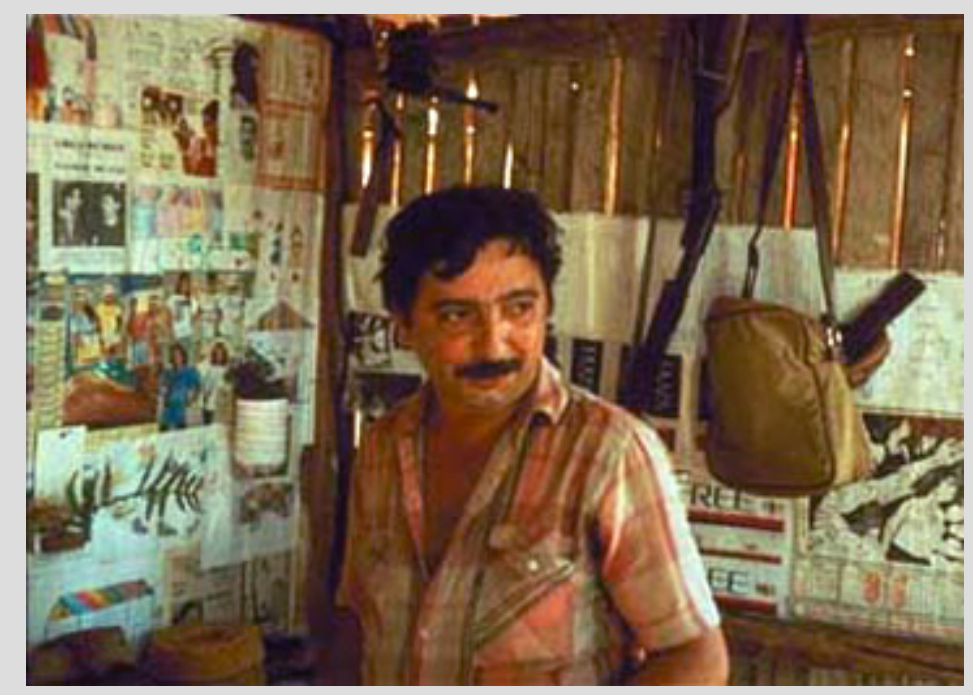

Nem o Chico Mendes sobreviveu. 


\section{Gilberto Gil (1995)}

Quanta do latim

Piural de quantum

Quando quase não há

Quantidade que se medir

Qualidade que se expressar

Fragmento infinitésimo

Quase que apenas mental Quantum granulado no mel Quantum ondulado do sal. Mel de urânio, sal de rádio Qualquer coisa quase ideal

Cântico dos cânticos Quântico dos quânticos

(...)

Sei que a arte é irmã da ciência Ambas filhas de um Deus fugaz Que faz num momento e no mesmo momento desfaz. 


\section{ALGUMAS CONCLUSÕES}

- Interesse relativamente grande em C\&T.

- Maior interesse: Informática e novas descobertas em C\&T.

- $\quad$ Consumo pequeno de C\&T nos diversos meios de comunicação.

- Visitação a museus e participação em eventos: baixa. Exclusão social.

- $\quad$ Avaliação positiva do avanço da ciência no Brasil: estágio "intermediário".

- Áreas mais importantes de pesquisa em C\&T: medicina, agricultura, energia.

- Divisão social nas avaliações.

- Desconhecimento grande de cientistas e instituições locais.

- Ciência não é neutra. I mportância da participação popular. 


\section{Brasília- Semana Nacional de C\&T - 2006}

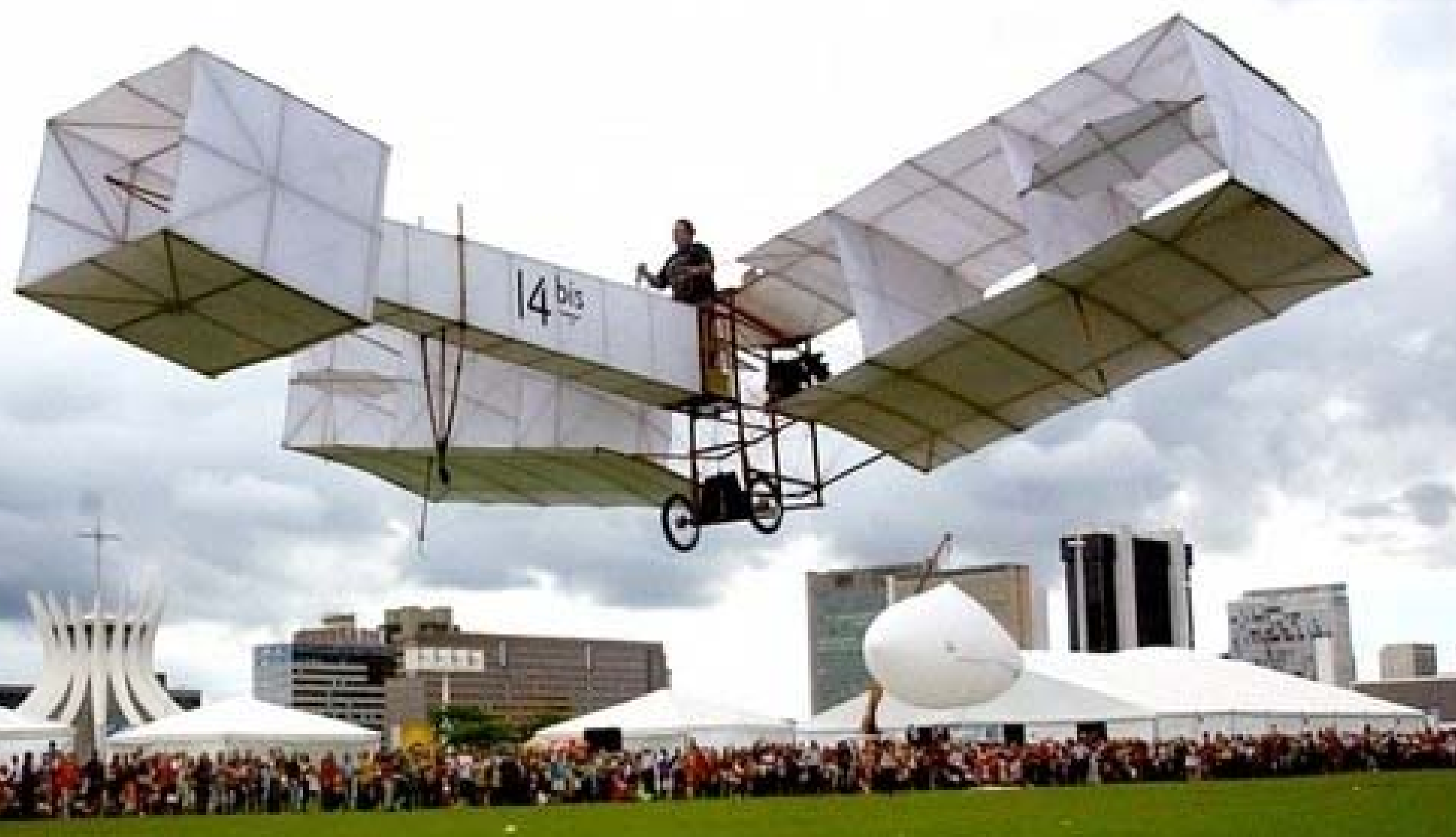




\section{Semana Nacional de Ciência e Tecnologia}

20 a 26 de outubro de 2008

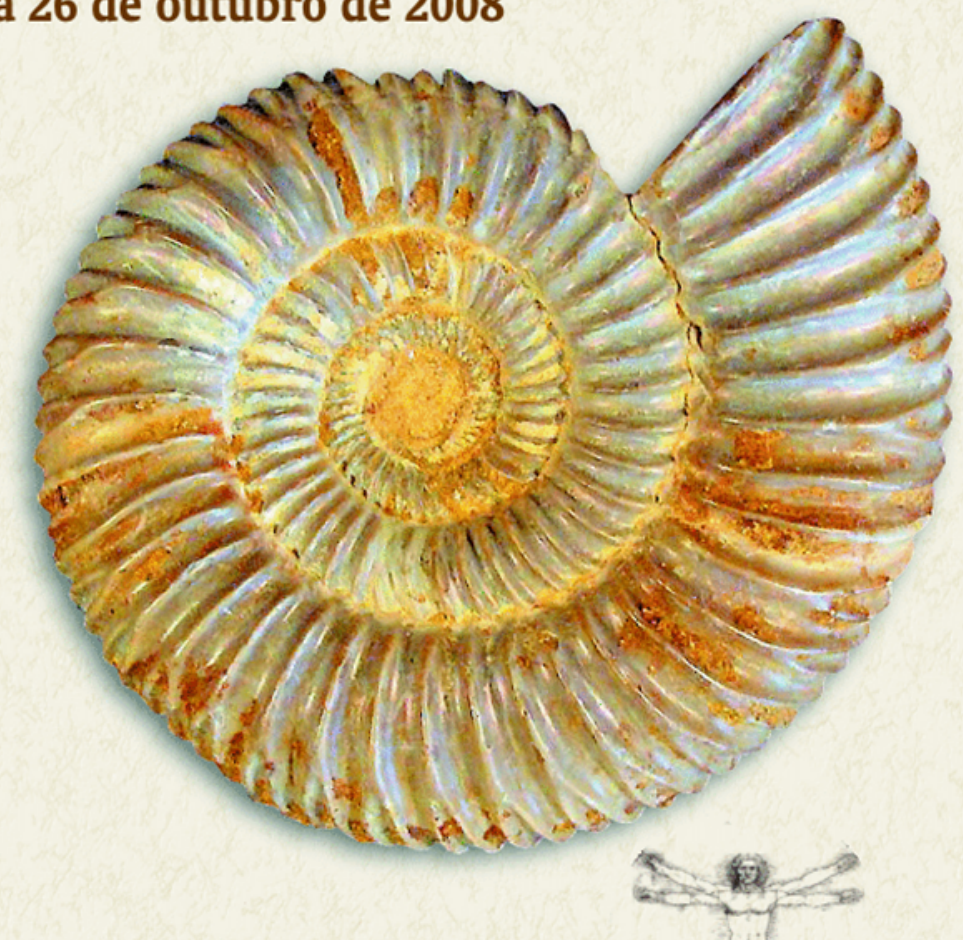

Evolução \& Diversidade

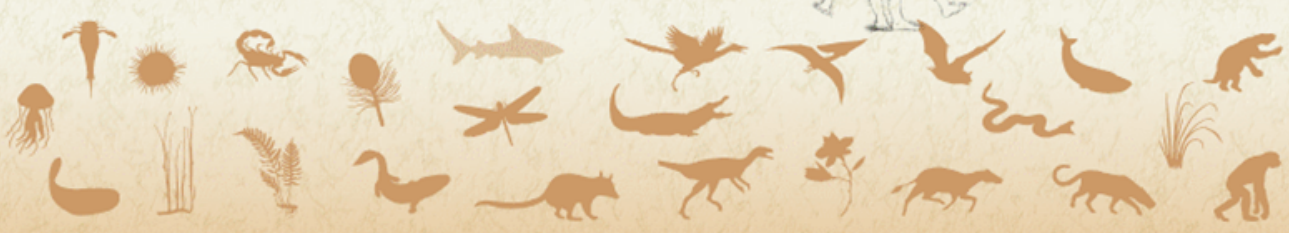

\section{Semana Nacional} de Ciência e Tecnologia

20 a 26 de outubro de 2008

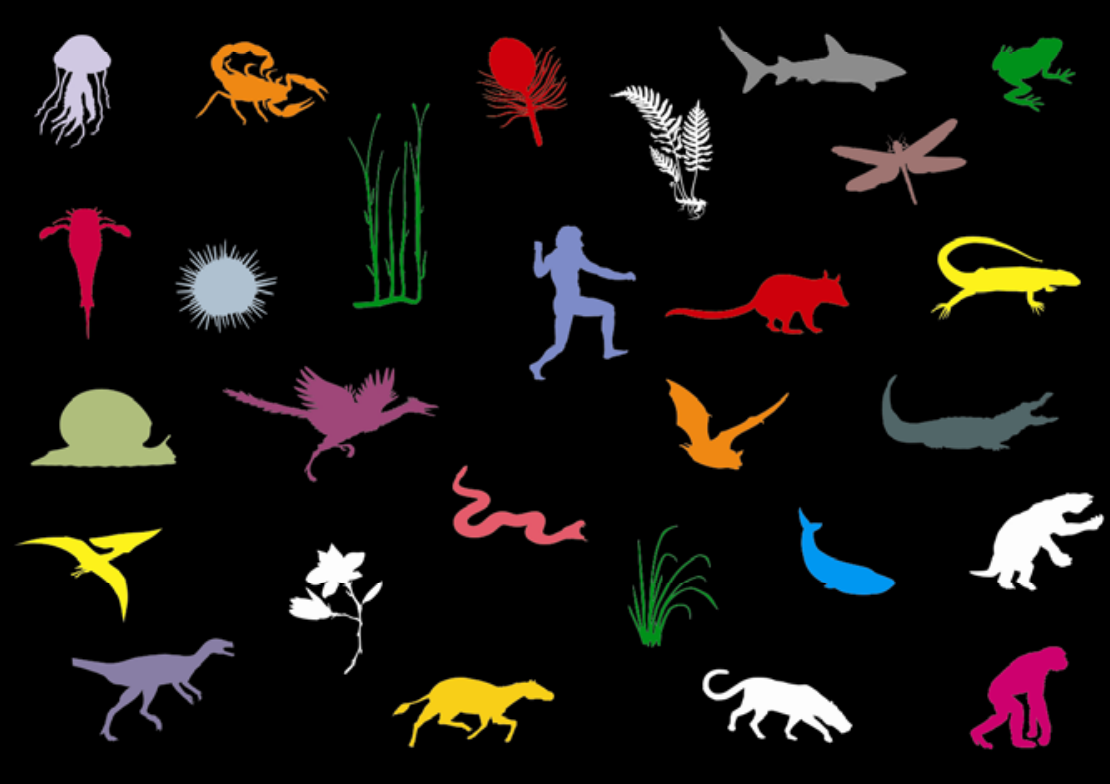

Evolução \& Diversidade Participe! Organize atividades na sua escola. 


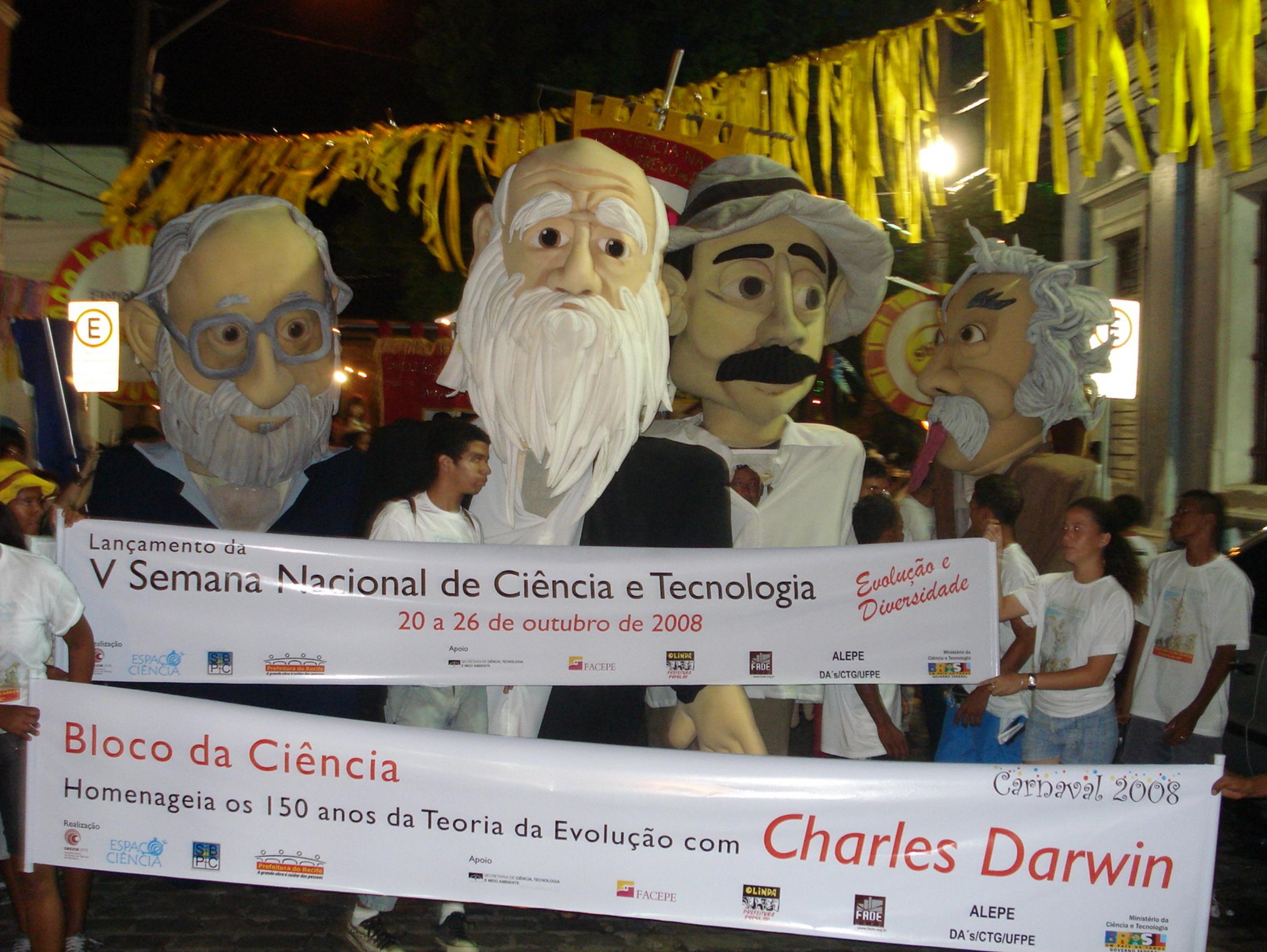




\section{Conclusões / encaminhamentos:}

As FAPs pouco financiam divulgação

científica; preocupam-se com a popularização

$$
\text { da C,T\&l . }
$$

- Resultados de pesquisas científicas e tecnológicas de interesse (pesquisa de ponta): publicação garantida! 


\section{Necessitam apoio e fomento:}

- Áreas com dificuldade de publicar: impacto local ou, no máximo, regional.

- Propostas inovadoras (diferentes das existentes), que sejam abrangentes ( não atreladas a um

Departamento ou Programa de PG ou Instituição). 


\section{Necessitam apoio e fomento:}

- Propostas de melhoria do ensino: realidade nacional (debates, reflexões, procedimentos didáticopedagógicos que contribuam para a melhoria do ensino das diferentes áreas do conhecimento).

\section{Ver QNEsc!}




\section{Discutir (FAPESC):}

- Política estratégica de apoio à divulgação científico-

tecnológica de interesse do Estado (em

consonância com SEER, I NSEER e repositórios),

exclusivamente por veiculação eletrônica.

- Difundir/praticar o jornalismo científico

(popularização da C,T\&l). 
FAPESC

\section{Obrigado!}

\section{czucco@fapesc.sc.gov.br}

